\title{
HUBUNGAN OBESITAS DAN POLA AKTIVITAS DENGAN HIPERTENSI DI WILAYAH KERJA PUSKESMAS III DENPASAR UTARA
}

\author{
RELATIONSHIP OF OBESITY AND ACTIVITY \\ PATTERNS WITH HYPERTENSION IN PUSKESMAS \\ III NORTH DENPASAR WORK AREA
}

\author{
Ni Made Sri Damayanti ${ }^{1}$, Ns. Ni Putu Wiwik Oktaviani, S.Kep., M.Kep², \\ Ns. Ni Ketut Ayu Mirayanti, S.Kep., M.Kep ${ }^{3}$ \\ Sekolah Tinggi Ilmu Kesehatan Wira Medika Bali ${ }^{123}$
}

\begin{abstract}
ABSTRAK
Hipertensi merupakan suatu keadaan yang menyerang usia produktif dari umr $35-60$ tahun yang semakin meningkat dari tahun ke tahun. Faktor kemunculan hipertensi ada dua faktor yaitu faktor yang dapat dikontrol dan tidak dapat dikontrol misalnya obesitas dan aktivitas fisik. Tekanan darah tinggi tidak bisa disembuhkan tetapi bisa dikontrol dengan cara pencegahan primer dan pencegahan sekunder. Tujuan penelitian ini adalah untuk mengetahui tentang hubungan antara obesitas dan pola aktivitas dengan hipertensi di Wilayah Kerja Puskesmas III Denpasar Utara. Metode yang digunakan dalam penelitian ini yaitu deskriftif korelasional dengan pendekatan cros sectional dengan tehnik pengambilan sampel non probability sampling dengan tehnik purposive sampling. Analisis data menggunakan uji rank spearman. Hasil uji statistik didapatkan $r$ hitung $=0,426$ dan $p$-value $=0,001$ atau $p \leq 0,05$. Hasil uji statistik didapatkan bahwa $\mathrm{r}$ hitung $=-0,421$ dan $p$ value $=0,001$ atau $p \leq 0,05$. Hasil Penelitian ini menunjukkan bahwa terdapat hubungan antara obesitas dan pola aktivitas dengan hipertensi di wilayah kerja puskesmas III denpasar utara, oleh karena itu diharapkan kepada tenaga medis khususnya keperawatan dapat meningkatkan pelayanan kesehatan khususnya program promotif dan preventif serta penyuluhan mengenai faktor-faktor risiko yang dapat menyebabkan terjadinya hipertensi.
\end{abstract}

Kata Kunci:Obesitas, Pola Aktivitas, Hipertensi

\begin{abstract}
Hypertension is a condition which attacks productive age between 35 to 60 years old which is increasing from year to year. Hypertension is caused by two factors, there are controled factor and uncontrolled factor such as obesity and physical activity. High blood pressure cannot be healed but is can be controled by premier prevention and secondary prevention. The purpose of this study was to find out about the relationship between obesity and activity patterns with hypertension in the working area of Puskesmas III North Denpasar. The method used on this research is correctional descriptive with cross sectional approach by taking the non probability sampling and purposive samplic technic. The data analysis is using rank spearman test. The statistic test result obtained is $r=0,426$ and $p$-value $=0.001$ or $p \leq 0,05$. The statistic test result obtained is $r=-0,421$ and $p$-value $=0.001$ or $p \leq 0,05$. Its means that there is a correlation of obesity and activity patterns with hypertension in
\end{abstract}


Bali Medika Jurnal.

Vol 7 No 1, 2020: 24-34

ISSN : 2615-7047

DOI: https://doi.org/10.36376/bmj.v7i1

the working area of puskesmas III denpasar utara, therefore it is expected that medical personnel, especially nursing, can improve health services, especially promotive and preventive programs and counseling about risk factors that can cause hypertension

Keywords: Obesity, Activity Pattern, Hypertension

\begin{tabular}{ll}
\hline Alamat Korespondensi & :Desa Ngis, Banjar Pekarangan, Manggis, Karangasem, Bali, \\
& 80871 \\
Email & $:$ madesri611@gmail.com \\
\hline
\end{tabular}

\section{PENDAHULUAN}

Penyakit tidak menular saat ini semakin bergeser ke usia muda selama dua dekade terakhir ini telah terjadi transisi epidemiologis yang signifikan, penyakit tidak menular telah menjadi beban utama seperti penyakit hipertensi sudah banyak menyerang orang di usia produktif. Rata-rata penyakit ini mulai menyerang usia 30-40 tahun bahkan lebih muda dari itu (Depkes RI, 2018). Menurut World Health Organization (WHO) tahun 2015 menunjukkan sekitar 1,13 Miliar orang di dunia menyandang hipertensi, artinya 1 dari 3 orang di dunia terdiagnosis hipertensi (WHO, 2015). Setiap tahun penyakit hipertensi jumlahnya semakin meningkat tahun 2025 orang yang terkena hipertensi diperkirakan ada 1,5 miliyar. Setiap tahun angka kematian akibat penyakit hipertensi sendiri diperkirakan mencapai 9,4 juta per tahunnya (Kemenkes RI, 2015). Penyakit hipertensi ini sering disebut pembunuh diam-diam atau (silent killer karena tidak memberikan gejala yang khas, tetapi bisa meningkatkan terjadinya kejadian stroke, serangan jantung, penyakit ginjal kronik bahkan dapat menyebabkan kebutaan jika tidak dikontrol dan dikendalikan dengan baik (Yonata \& Pratama, 2016).

Obesitas telah menjadi pandemik World Health Organization (WHO, 2015) sebagai masalah kesehatan kronis terbesar pada orang dewasa. Sekitar 1,6 miliar orang dewasa di seluruh dunia mengalami berat badan berlebih (overweight) dan sekurang kurangnya 400 juta diantaranya mengalami obesitas. WHO (2015) menyatakan pada tahun 2010 , di Indonesia tercatat 78,2 juta penduduk $(32,90 \%)$ mengalami kegemukan, sementara 9,8 juta penduduk (4,10\%) mengalami obesitas. Kasus obesitas tertinggi pada tahun 2015 terletak di Kota Surabaya dengan total kasus sebanyak 57. 987 kasus dan pada tahun 2016 terletak di Kabupaten Banyuwangi dengan total kasus sebanyak 63. 614 kasus (Ramadhani \& Sulistyorini, 2018). Prevalensi obesitas di Indonesia pada tahun 2018 dengan berat badan berlebih sebanyak 14,8 kasus dan pravalensi obesitas sentral pada umur $\geq 15$ tahun sebanyak 31,0\%. Provinsi bali pada tahun 2018 sebesar 41,5\% kasus obesitas (Depkes RI, 2018).

Obesitas merupakan salah satu faktor pemicu kemunculan hipertensi. Faktor-faktor pemicu kemunculan hipertensi dapat dibedakan menjadi dua yaitu faktor yang tidak dapat dikontrol dan faktor yang dapat di kontrol seperti kegemukan/obesitas. Obesitas dapat menyebabkan peningkatan cardiac output, karena makin besar massa tubuh maka makin banyak jumlah darah yang beredar mengakibatkan curah jantung meningkat. Dimana bila tubuh seseorang semakin besar maka volume darah yang dibutuhkan untuk memasok oksigen ke dalam makanan dan jaringan tubuh akan semakin meningkat. Hal ini yang menyebabkan 
jantung akan bekerja lebih keras, sehingga tekanan darah meningkat secara tidak langsung melalui perangsangan aktivitas sistem saraf simpatis dan Renin Angiotensin Aldosteron System (RAAS). Keadaan ini menyebabkan timbulnya penyakit hipertensi (Ramadhani \& Sulistyorini, 2018).

Hipertensi merupakan salah satu masalah kesehatan serius yang membutuhkan perhatian karena penyakit hipertensi dapat menyebabkan kematian terutama di negara-negara maju dan negara berkembang. World Health Organization mencatat pada tahun 2015 menunjukkan sekitar 1,13 miliar orang di dunia menderita hipertensi. Jumlah penderita hipertensi di dunia saat ini terus meningkat setiap tahunnya diperkirakan 1,5 miliar kasus pada tahun 2025 atau sekitar 29\% dari orang dewasa penduduk dunia menderita hipertensi. Prevalensi hipertensi paling tinggi terdapat di wilayah Afrika sebanyak $46 \%$ dan prevalensi terendah di wilayah Amerika sebanyak 35\%. Hampir sepertiga dari total jumlah populasi orang dewasa di wilayah asia Tenggara mengalami penyakithipertensi. Berdasarkan hasil Riset Kesehatan Dasar (2018), menyebutkan bahwa prevalensi hipertensi di Indonesia cenderung meningkat menjadi 34,1\% yang didapat melalui pengukuran tekanan darah pada usia 18 tahun ke atas. Di Indonesia kota Sulawesi Utara paling tinggi dengan pravalensi yang mengalami hipertensi sebesar 13,2\% dan Yogyakarta dengan prevalensi 12,5\% yang mengalami hipertensi (Mahmudah et al., 2016). Dinas Kesehatan Provinsi Bali tentang penyakit hipertensi, tercatat kasus hipertensi jumlah pasien hipertensi tahun 2014 sebanyak 22. 837 kasus, pada tahun 2015 sebanyak 29. 867 kasus dan pada tahun 2016 sebanyak 35.859 kasus (Candra et al., 2016). Berdasakan data yang diperoleh dari Dinas Kesehatan Provinsi Bali pada tahun 2018-2019 Pravalensi di Bali yang mengalami hipertensi pra lansia 45-59 tahun yaitu 495. 166 kasus. Kota Denpasar menduduki peringkat yang ke 7 dengan prevalensi hipertensi sebesar 44. 172 kasus yang mengalami hipertensi.

Aktivitas fisik sangat memengaruhi stabilitas tekanan darah. Seseorang yang tidak aktif dalam melakukan suatu kegiatan cenderung akan mempunyai frekuensi denyut jantung yang lebih tinggi. Hal tersebut akan mengakibatkan otot jantung bekerja lebih keras pada setiap kontraksi. Makin keras otot jantung dalam memompa darah, makin besar pula tekanan darah yang membebankan pada dinding arteri sehingga tahanan perifer yang menyebabkan kenaikan tekanan darah. Kurangnya aktivitas fisik juga dapat meningkatkan risiko kelebihan berat badan yang akan menyebabkan risiko hipertensi meningkat (Andriani, 2017).

Data yang didapatkan dari rekam medis pasien di Wilayah Kerja Puskesmas III Denpasar Utara tahun 2017 adalah jumlah penderita hipertensi keseluruhan lakilaki 347 orang $(64,2 \%)$ dan perempuan 359 orang $(69,4 \%)$. Jumlah penderita meningkat pada tahun 2018 dengan jumlah laki - laki 426 orang $(59,2 \%)$ dan perempuan 410 orang $(51,9 \%)$. Jumlah penderita hipertensi pada bulan juli 2019 65 pasien dengan 32 orang $(47,7 \%)$ laki laki 33 orang $(51,2 \%)$ perempuan termasuk dalam kunjungan kasus lama. Berdasarkan fenomena tersebut peneliti akan melakukan penelitian tentang hubungan antara obesitas dan pola aktivitas dengan hipertensi di Wilayah Kerja Puskesmas III Denpasar Utara. 


\section{METODE PENELITIAN}

Penelitian ini merupakan peneltian bersifat kuantitatif dengan desain penelitian yang digunakan yaitu deskriptif korelasionaldengan pendekatan cross sectional. Pendekatan cross sectional adalah jenis penelitian yang menekankan waktu pengukuran atau observasi data variabel independen dan dependen hanya satu kali pada satu saat (Nursalam, 2015). Populasi yang diambil dalam penelitian ini adalah penderita hipertensi dan obesitas di Wilayah Kerja Puskesmas III Denpasar Utara pada bulan 2019 sebanyak 65 responden.

Penelitian ini telah dilakukan di Wilayah Kerja Puskesmas III Denpasar Utara, waktu penelitian dilakukan Pada Tanggal 1 September 2019 sampai 30 November 2019. Variabel independen dalam penelitian ini adalah obesitas dan pola aktivitas. Variabel dependen dalam penelitian ini adalah Hipertensi. Instrumen atau alat pengumpulan data pada penelitian ini menggunakan format pengumpulan data untuk mengidentifikasi karakteristik responden yaitu umur, jenis kelamin dan pekerjaan, timbangan yang sudah dilakukan kalibrasi dengan no surat 510.3/2603/disperindag yaitu dengan kapasitas $180 \mathrm{~kg}$ untuk mengukur berat badan, meteran untuk mengukur tinggi badan untuk mengukur obesitas dengan cara berdiri dan sphygmomanometer yang telah dikalibrasi dengan nomor surat AKL 20501901181 yang masih berfungsi baik dan kuesioner aktivitas fisik (International Physical Activity Quisitionnaire/IPAQ. Skor aktivitas fisik dihitung sesuai dengan protocol skoring IPAQ dan dinyatakan dalam satuan MET (Metabolik Energy Turnover) -menit/minggu. Deskripsi tingkat aktivitas dalam tabel distribusi frakuensi yang diadopsi dari IPAQ, yaitu rendah $(<600 \mathrm{MET}-$ menit/minggu), sedang (600-2999 MET-menit/minggu) dan tinggi ( $\geq 3000 \mathrm{MET}$ menit/minggu). Obesitas dan pola aktivitas dengan hipertensi menggunakan skala ordinal. Tehnik analisis univariat dan bivariat dengan tingkat signifikan nilai $a \leq$ 0,05 .

\section{HASIL DAN PEMBAHASAN}

\section{HASIL}

Tabel 1. Karakteristik Subyek Penelitian Berdasarkan Jenis Kelamin

\begin{tabular}{lcc}
\hline \multicolumn{1}{c}{ Jenis Kelamin } & F & \% \\
\hline Laki-laki & 24 & 42.86 \\
Perempuan & 32 & 57.14 \\
\hline \multicolumn{1}{c}{ Total } & 56 & 100.00 \\
\hline
\end{tabular}

Berdasarkan tabel 1diatas menunjukkan bahwa sebagian besar responden berjenis kelamin perempuan yaitu sebanyak 32 orang $(57,14 \%)$.

Table 2. Karakteristik Subyek Penelitian Berdasarkan Usia

\begin{tabular}{ccc}
\hline Umur & F & \% \\
\hline 35-44 tahun & 12 & 21.42 \\
45-54 tahun & 20 & 35.71 \\
$55-60$ tahun & 24 & 42.85 \\
\hline Total & 56 & 100.00 \\
\hline
\end{tabular}


Bali Medika Jurnal.

Vol 7 No 1, 2020: 24-34

ISSN : 2615-7047

DOI: https://doi.org/10.36376/bmj.v7i1

Berdasarkan Tabel 2 menunjukkan bahwa dari keseluruhan responden sebagian besar responden berada pada kelompok umur 55-60 tahun yaitu sebanyak 24 orang $(42,85 \%)$.

Table 3. Karakteristik Subyek Penelitian Berdasarkan Pekerjaan

\begin{tabular}{|c|c|c|}
\hline Pekerjaan & $\mathbf{F}$ & $\%$ \\
\hline PNS & 11 & 19.65 \\
\hline Swasta & 20 & 35.71 \\
\hline Wiraswasta & 10 & 17.86 \\
\hline Petani & 3 & 5.35 \\
\hline Tidak bekerja & 12 & 21.43 \\
\hline Total & 56 & 100.00 \\
\hline
\end{tabular}

Berdasarkan Tabel 3 menunjukkan bahwa dari keseluruhan responden sebagian besar responden memiliki pekerjaan sebagai swasta yaitu sebanyak 20 orang $(35,71 \%)$.

Tabel 4. Obesitas di Wilayah Kerja Puskesmas III Denpasar Utara

\begin{tabular}{lccc}
\hline \multicolumn{2}{c}{ Obesitas } & F & \% \\
\hline $\begin{array}{l}\text { Kelebihan } \\
\text { berisiko }\end{array}$ & BB (Overweight) & 9 & 16.07 \\
$\begin{array}{l}\text { Obesitas I } \\
\text { Obesitas II }\end{array}$ & & 29 & 51.78 \\
\hline \multicolumn{2}{r}{ Total } & 18 & 32.15 \\
\hline
\end{tabular}

Berdasarkan tabel 4 menunjukkan bahwa dari keseluruhan responden sebagian besar responden memiliki berat badan dalam kategori obesitas I, yaitu sebanyak 29 orang $(51,78 \%)$.

Tabel 5. Pola Aktivitas di Wilayah Kerja Puskesmas III Denpasar Utara.

\begin{tabular}{ccc}
\hline Pola Aktivitas & F & \% \\
\hline Aktivitas Fisik Kurang & 0 & 0 \\
Aktivitas Fisik Sedang & 7 & 12.50 \\
Aktivitas Fisik Berat & 49 & 87.50 \\
\hline Total & 56 & 100.00 \\
\hline
\end{tabular}

Berdasarkan tabel 5 menunjukkan bahwa dari keseluruhan responden sebagian besar responden memiliki aktivitas berat, yaitu sebanyak 49 orang $(87,50 \%)$.

Tabel 6. Kejadian Hipertensi di Wilayah Kerja Puskesmas III Denpasar Utara

\begin{tabular}{ccc}
\hline Derajat Hipertensi & F & \% \\
\hline Hipertensi Tahap 1 & 31 & 55.36 \\
Hipertensi Tahap 2 & 25 & 44.65 \\
\hline Total & 56 & 100.00 \\
\hline
\end{tabular}

Berdasarkan tabel 6 menunjukkan bahwa dari keseluruhan responden sebagian besar responden memiliki hipertensi tahap 1, yaitu sebanyak 31 orang $(55,36 \%)$ 
Tabel 7. Analisis Hubungan Obesitas Dengan Hipertensi di Wilayah Kerja Puskesmas III

Denpasar Utara

\begin{tabular}{|c|c|c|c|c|c|c|c|c|c|}
\hline \multirow[t]{2}{*}{ Obesitas } & \multicolumn{5}{|c|}{ Kejadian Hipertensi } & \multicolumn{2}{|c|}{ Total } & \multirow[t]{2}{*}{ P-value } & \multirow[t]{2}{*}{$\begin{array}{c}\text { Correlation } \\
\text { Coefficient }\end{array}$} \\
\hline & & $\mathbf{F}$ & $\%$ & $\mathbf{F}$ & $\%$ & $\mathbf{F}$ & $\%$ & & \\
\hline $\begin{array}{l}\text { Kelebihan } \\
\text { berisiko }\end{array}$ & BB & 8 & 14.29 & 1 & 1.78 & 9 & 16.07 & & \\
\hline Obesitas I & & 18 & 32.14 & 11 & 19.64 & 29 & 51.78 & 0,001 & 0,426 \\
\hline Obesitas II & & 5 & 8.93 & 13 & 23.22 & 18 & 32.15 & & \\
\hline Total & & 31 & 55.36 & 25 & 44.65 & 56 & 100.00 & & \\
\hline
\end{tabular}

Berdasarkan Hasil analisis bivariat obesitas dengan hipertensi di Wilayah Kerja Puskesmas III Denpasar Utara menunjukkan nilai $p$-value $=0,001$ atau $p \leq 0,05$ dengan nilai koefisien korelasi $(\mathrm{r})=0,426$. Hasil ini mengindikasikan bahwa Ho penelitian ditolak yang berarti ada hubungan yang antara obesitas dengan hipertensi di Wilayah Kerja Puskesmas III Denpasar Utara dengan kekuatan korelasi sedang dan arah hubungan positif yang berarti semakin meningkat berat badan (semakin tinggi tingkat obesitas), maka semakin tinggi derajat hipertensi. Sebaliknya, semakin ringan tingkat obesitas maka semakin ringan juga derajat hipertensi.

Tabel 8. Analisis Hubungan Pola Aktivitas Dengan Hipertensi di Wilayah Kerja Puskesmas III Denpasar Utara

\begin{tabular}{|c|c|c|c|c|c|c|c|c|}
\hline \multirow{3}{*}{ Pola Aktivitas } & \multicolumn{4}{|c|}{ Kejadian Hipertensi } & \multirow{2}{*}{\multicolumn{2}{|c|}{ Total }} & \multirow{3}{*}{$\begin{array}{c}P- \\
\text { value }\end{array}$} & \multirow{3}{*}{$\begin{array}{c}\text { Correlat } \\
\text { on } \\
\text { Coefficie } \\
\text { nt }\end{array}$} \\
\hline & \multicolumn{2}{|c|}{$\begin{array}{c}\text { Hiperten } \\
\text { si Tahap } \\
\text { I }\end{array}$} & \multicolumn{2}{|c|}{$\begin{array}{c}\text { Hiperten } \\
\text { si Tahap } \\
2\end{array}$} & & & & \\
\hline & $\mathbf{F}$ & $\%$ & $\mathbf{F}$ & $\%$ & $\mathbf{F}$ & $\%$ & & \\
\hline $\begin{array}{l}\text { Aktivitas } \\
\text { Kurang }\end{array}$ & 0 & 0 & 0 & 0 & 0 & 0 & & \\
\hline $\begin{array}{l}\text { Aktivitas } \\
\text { Sedang }\end{array}$ & 0 & 0 & 7 & $\begin{array}{l}12,5 \\
0\end{array}$ & 7 & 2. 50 & $\begin{array}{l}0,00 \\
1\end{array}$ & $-0,421$ \\
\hline Aktivitas Fisik Berat & $\begin{array}{l}3 \\
1 \\
\end{array}$ & $\begin{array}{l}55,3 \\
6 \\
\end{array}$ & $\begin{array}{l}1 \\
8 \\
\end{array}$ & $\begin{array}{c}32,1 \\
4 \\
\end{array}$ & 49 & $\begin{array}{l}87 . \\
50\end{array}$ & & \\
\hline Total & 31 & 55,36 & 25 & 44.64 & 56 & 100.00 & & \\
\hline
\end{tabular}

Berdasarkan Hasil analisis bivariat hubungan pola aktivitas dengan hipertensi di Wilayah Kerja Puskesmas III Denpasar Utara menunjukkan nilai $p$ value $=0,001$ atau $p \leq 0,05$ dengan nilai koefisien korelasi $(\mathrm{r})=-0,421$. Hasil ini mengindikasikan bahwa Ho penelitian ditolak yang berarti ada hubungan hubungan pola aktivitas dengan hipertensi di Wilayah Kerja Puskesmas III Denpasar Utara dengan kekuatan korelasi sedang dan arah hubungan negatif yang berarti semakin rendah aktivitas fisik, maka semakin berat derajat hipertensi yang dialami. Sebaliknya, semakin berat aktivitas fisik maka semakin rendah derajat hipertensi. 


\section{PEMBAHASAN}

\section{Hubungan Obesitas Dengan Hipertensi Di Wilayah Kerja Puskesmas III Denpasar Utara}

Hasil penelitian didapatkan bahwa responden dengan obesitasI tetapi memiliki kategori hipertensi tahap II sebanyak 11 orang (19. 64\%) dari total responden 29 orang (51.78\%) yang memiliki obesitas I. Peningkatan terjadinya obesitas pada hipertensi tahap I ini disebabkan oleh karakteristik usia yang dimiliki responden.

Peningkatan obesitas I pada hipertensi tahap II sebanyak 11 orang (19. 64\%), peningkatan ini disebabkan karena Terdapat beberapa faktor risiko lain yang berperan terjadinya obesitas antara lain faktor genetik, faktor lingkungan, usia, faktor psikososial, obat-obatan, faktor perkembangan, faktor kesehatan,aktivitas fisik dan ekonomi (Proverawati, 2010). Hal ini menunjukkan bahwa faktor usia, sangat mempengaruhi terjadinya obesitas, dimana semakin bertambahnya usia maka tingkat metabolisme semakin menurun. Hal ini dikarenakan hilangnya sebagian jaringan otot serta perubahan hormonal dan neurologis, akibatnya kecepatan tubuh dalam membakar kalori pun berkurang. Bertambahnya umur seseorang maka terjadi penurunan fungsi fisiologis dan daya tahan tubuh yang terjadi karena proses penuaan yang dapat menyebabkan seseorang rentan terhadap penyakit salah satunya yaitu hipertensi (Adnani, 2011).

Hasil analisis bivariat obesitas dengan hipertensi di Wilayah Kerja Puskesmas III Denpasar Utara menunjukkan nilai $p$-value $=0,001$ atau $p \leq 0,05$ dengan nilai koefisien korelasi (r) $=0,426$. Hasil ini mengindikasikan bahwa Ho penelitian ditolak yang berarti ada hubungan yang antara obesitas dengan hipertensi di Wilayah Kerja Puskesmas III Denpasar Utara dengan kekuatan korelasi sedang dan arah hubungan positif.

Obesitas adalah suatu faktor resiko lain yang sangat menentukan terjadinya tingkat keparahan hipertensi. Obesitas adalah suatu faktor resiko lain yang sangat menentukan terjadinya tingkat keparahan hipertensi. Semakin besar tubuh seseorang, maka semakin banyak darah yang akan dibutuhkan untuk menyuplai oksigen dan nutrisi ke otot dan jaringan lain. Obesitas dapat menyebabkan terjadinya peningkatkan jumlah panjangnya pembuluh darah, hal ini dapat meningkatkan resistensi darah yang seharusnya mampu menempuh jarak lebih jauh. Peningkatan resistensi dapat menyebabkan tekanan darah menjadi lebih tinggi. Kondisi ini dapat dapat diperparah oleh sel-sel lemak yang memproduksi senyawa yang dapat merugikan jantung dan pembuluh darah (Kowalski, 2010). Jaringan lemak merupakan jaringan ikat yang mempunyai fungsi sebagai tempat penyimpanan lemak dalam bentuk trigliserida. Fungsi utama jaringan lemak yaitu sebagai tempat penyimpanan energi dalam bentuk trigliserida dan melepaskannya sebagai asam lemak bebas dan gliserol yang merupakan sumber energi yang berasal dari lemak.Akumulasi lemak ditentukan oleh keseimbangan antara (lipogenesis) dan pemecahan lemak (liposis-oksidasi asam lemak). Meningkatnya kolestrol LDL dapat menyebabkan penyempitan pembuluh darah dan terjadi pembekuan darah sehingga aliran di pembuluh darah arteri meningkat (Pudjiastuti, 2013).

Hasil penelitian yang didapat sesuai dengan hasil penelitian (Herdiani, 2019), tentang hubungan imt dengan hipertensi pada lansia di kelurahan gayungan 
Surabaya 2019. Hasil penelitian menunjukkan $\mathrm{p}$ sebesar 0,000 dimana $\mathrm{p}<0,05$ yang berarti adanya hubungan yang signifikan antara Indeks Massa Tubuh (IMT) dengan hipertensi pada lansia hipertensi. Hasil penelitian yang didapatkan oleh (Hasanah et al., 2016), tentang hubungan obesitas dengan hipertensi pada masyarakat di wilayah Rw 13 dusun mojosari desa ngenep kecamatan karangploso. Menunjukkan nilai $p$-value $<\alpha(0.000<0.05)$ dan koefisien korelasi sebesar 0.845 yang membuktikan bahwa hubungan obesitas dengan tekanan darah merupakan hubungan yang sangat kuat. Hasil penelitian yang dilakukan oleh (Ramadhani \& Sulistyorini, 2018), tentang hubungan kasus obesitas dengan hipertensi di provinsi jawa timur tahun 2015-2016, menunjukkan bahwa nilai signifikansi sebesar 0,01 (p $=0,01)$ sehingga $\mathrm{p}<\alpha$ yang berarti terdapat hubungan antara kasus obesitas dengan kasusKasus hipertensi di Provinsi Jawa Timur tahun 2015-2016. Hasil penelitian yang dilakukan oleh (Yanti et al., 2018), tentang hubungan obesitas engan hipertensi pada oang dewasa menunjukkan bahwa hasil uji statistik didapatkan nilai $\mathrm{p}$ value 0,031 yang artinya ada hubungan antara obesitas dengan kejadian hipertensi, nilai OR-nya yaitu 4. 375 yang artinya pasien dewasa akan beresiko atau berpeluang mengalami hipertensi sebanyak $4.375 \approx 4$ kali dibandingkan pada pasien yang bukan dewasa. Sedangkan penelitian yang dilakukan oleh (Ulumuddin \& Yhuwono, 2018), tentang hubungan indeks masa tubuh dengan tekanan darah pada lansia didesa pesucen banyuangi menunjukkan bahwa hasil $p$-value $=0,029$; dengan $r$ hitung $=0,154)$ dan $(p$-value $=0,009$; dengan $r$ hitung $=0,183)$. Kedua nilai tersebut menunjukkan bahwa terdapat hubungan antara indeks massa tubuh dengan tekanan darah sistol maupun diastolik, namun dengan kekuatan hubungan yang lemah.

Menurut pendapat peneliti,dari hasil observasi didapatkan penumpukan lemak banyak terjadi pada perut, lengan, paha. Hal ini disebabkan karena pada responden yang sudah memiliki obesitas cenderung tidak memperhatikan diet yang dilakukan yang seharusnya dikurangi makan makanan yang berlemak tetapi mereka meningkatkan konsumsi diet lemak yang harus dikurangi. Penumpukan lemak yang disebabkan oleh diet yang dikurangi. Peneumpukan lemak yang disebabkan oleh diet yang tidak teratur dapat menyebabkan penumpukan lemak di dalam tubuh. Hal ini dapat menyebabkan kerja jantung di dalam tubuh akan semakin meningkat akibat dari penumpukan lemak yang dapat berdampak pada tekanan darah yang akan semakin meningkat.

\section{Hubungan Pola Aktivitas Dengan Hipertensi Di Wilayah Kerja Puskesmas III Denpasar Utara}

Hasil penelitian didapatkan bahwa responden dengan pola aktivitas fisik berat tetapi memiliki kategori hipertensi tahap II sebanyak 18 orang (32. 14\%) dari total responden 49 orang (87. 50\%) yang memiliki pola aktivitas fisik berat. Peningkatan pola aktivitas fisik berat pada hipertensi tahap II ini disebabkan oleh karakteristik pekerjaan yang dimiliki responden .

Hasil analisis bivariat hubungan pola aktivitas dengan hipertensi di Wilayah Kerja Puskesmas III Denpasar Utara menunjukkan nilai $p$-value $=0,001$ atau $p \leq 0,05$ dengan nilai koefisien korelasi $(r)=-0,421$. Hasil ini mengindikasikan bahwa Ho penelitian ditolak yang berarti ada hubungan hubungan pola aktivitas dengan hipertensi di Wilayah Kerja Puskesmas III Denpasar Utara dengan kekuatan korelasi sedang dan arah hubungan negatif. 
Aktivitas fisik merupakan suatu gerakan tubuh yang dapat dihasilkan oleh otot rangka yang memerlukan pengeluaran energi. Aktivitas fisik yang tidak ada (kurangnya aktivitas fisik) merupakan faktor risiko independen untuk terjadinya penyakit kronis, dan secara keseluruhan diperkirakan dapat menyebabkan kematian secara global (WHO, 2010). Proverawati (2010) menjelaskan bahwa seseorang dengan aktivitas fisik yang kurang meningkatkan prevalensi terjadinya obesitas. Orang-orang yang kurang aktif dalam melakukan kegiatan memerlukan kalori dalam jumlah sedikit dibandingkan orang yang memiliki aktivitas tinggi. Seseorang yang hidupnya kurang aktifatau tidak melakukan aktivitas fisik yang seimbang den mengkonsumsi makanan yang tinggi lemak, akan cenderung mengalami obesitas yang berdampak pada tekanan darah. Pada aktivitas fisik yang senantiasa aktif dan teratur akan menyebabkan pembuluh darah cenderung lebih elastis sehingga akan mengurangi tahanan perifer (Suiraoka, 2012). Aktivitas fisik juga melambatkan arterosklerosis yang sangat berperan dalam terjadinya gangguan kardiovaskular termasuk hipertensi. Aktivitas fisik dapat meningkatkan aliran darah ke jantung, menjaga elastisitas arteri dan fungsi arterial dan membuat tekanan darah terkontrol (Kowalski, 2010).

Hasil penelitian yang didapat sesuai dengan penelitian dari Sari et al. (2019) tentang hubungan antara kebiasaan mengonsumsi minuman berakohol dan aktivitas fisik dengan kejadian hiprtensi di desa karumenga kecamatan langowan utara kabupaten minahasa, yang menyatakan nilai $\mathrm{p}=0,005$ dimana nilai $\mathrm{p}<0,05$ sehingga Ho ditolak. Ho di tolak berarti terdapat hubungan abtara aktivitas fisik dengan kejadian hipertensi pada penduduk di Desa Karumenga Kecamatan Langowan Utara Kabupaten Minahasa Hasil penelitian yang dilakukan oleh Karim et al. (2018), tentang hubungan aktivitas fisik dengan derajat hipertensi di wilayah kerja puskesmas tagulandang kabupaten sitaro menunjukkan bahwa responden yang memiliki aktivitas fisik berat dengan derajat hipertsni stadium I sebanyak 5 orang $(62.5 \%)$. Hasil di peroleh nilai $p=0,039$. Atau probabilitas dibawah 0,05 . Dengan demikian Ha diterima yaitu ada hubungan antara aktivitas fisik dengan derajat hipertensi pada pasien rawat jalan di wilayah kerja Puskesmas Tagulandang Kabupaten SITARO. penelitian ini sejalan dengan penelitian Rihiantoro \& Widodo (2018) yang menemukan bahwa ada hubungan aktivitas fisik dengan kejadian hipertensi dengan $p$-value $=0,005$. Aktivitas fisik mempengaruhi stabilitas tekanan darah. Hasil penelitian yang dilakukan oleh Anggaraini et al. (2018), tentang hubungan pola aktivitas dan hipertensi di puskesmas rawasari kota jambi tahun 2018 uji statistik diperoleh nilai $\mathrm{p}=0,000$ mempunyai arti bahwa $\mathrm{p}<0,05$ yang artinya ho penelitian ditolak dengan kata lain terdapat hubungan antara aktivitas fisik dengan kejadian hipertensi.

Menurut pendapat peneliti dari hasil observasi di tempat penelitian didapatkan responden dengan pekerjaan swasta 20 orang dan kebanyakan dari hasil responden adalah berjenis kelamin perempuan. Seorang perempuan selain memiliki pekerjaan di luar rumah juga memiliki pekerjaaan tambahan mereka juga harus memenuhi kewajiban sebagai ibu rumah tangga yang memungkinkan menambah beban pekerjaan bagi mereka yang dapat menimbulkan stres akibat pekerjaaan. Dampak yang ditimbulkan dari stress tersebut dapat menyebabkan tekanan darah meningkat sehingga akan berdampak pada kejadian hipertensi. 


\section{Simpulan}

\section{SIMPULAN DAN SARAN}

Berdasarkan hasil penelitian di atas dapat dirumuskan kesimpulan sebagai berikut: Responden pada penelitian ini sebagian besar berjenis kelamin perempuan yaitu sebanyak 32 orang $(57,14 \%)$ dan tertinggi usia adalah 55-60 tahun dan usia terendah 35-44 tahun. Berdasarkan pekerjaan, sebagian besar responden yaitu sebanyak 20 orang $(35,71 \%)$ bekerja sebagai pegawai swasta. Tingkat obesitas responden menunjukkan bahwa sebagian besar responden memiliki berat badan dalam kategori obesitas I, yaitu sebanyak 29 orang (51,78\%). Pola aktivitas responden lebih banyak memiliki pola aktivitas berat, yaitu sebanyak 49 orang $(87,50 \%)$. Tingkat hipertensi responden sebagian responden memiliki hipertensi tahap 1, yaitu sebanyak 31 orang $(55,36 \%)$. Ada hubungan yang antara obesitas dengan hipertensi di Wilayah Kerja Puskesmas III Denpasar Utara dengan kekuatan korelasi sedang dan arah hubungan positif ( $p$-value $=0,001$ dan nilai koefisien korelasi $(r)=0,426)$. Ada hubungan pola aktivitas dengan hipertensi di Wilayah Kerja Puskesmas III Denpasar Utara dengan kekuatan korelasi sedang dan arah hubungan negatif ( $p$-value $=0,001$ dan nilai koefisien korelasi $(\mathrm{r})=-0,421)$.

\section{Saran}

Berdasarkan hasil penelitian yang didapatkan, peneliti mengusulkan beberapa saran, yaitu : Kepada Puskesmas III Denpasar Utara diharapkan dapat meningkatkan pelayanan kesehatan khususnya pengendalian penyakit hipertensi dengan cara melakukan pencegahan promotif dan preventif pada pasien hipertensi agar rajin minum obat hipertensi yang diberikan dan melakukan program penyuluhan mengenai hipertensi serta dapat meningkatkan kunjungan home visit setiap bulannya agar dapat memperkecil angka terjadinya hipertensi.

\section{DAFTAR PUSTAKA}

Adnani, H. (2011). Ilmu Kesehatan Masyarakat. Nuha Medika.

Anggaraini, S. D., Izhar, M. D., \& Noerjoedianto, D. (2018). Hubungan Antara Obesitas Dan Aktivitas Fisik Dengan Kejadian Hipertensi Di Puskesmas Rawasari Kota Jambi Tahun 2018. Jurnal Kesmas Jambi, 2(2).

Candra, I. W., Ruspawan, I. D. M., \& Sudiantara, I. K. (2016). Pengaruh Relaksasi Progresif Dan Meditasi Terhadap Tingkat Stres Pasien Hipertensi. 33, 102110.

Depkes RI. (2018). Hasil Utama Riskesdas 2018.

Hasanah, M., Widodo, D., \& Widiani, E. (2016). Hubungan obesitas dengan hipertensi pada masyarakat di wilayah RW 13 Dusun Mojosari Desa Ngenep Kecamatan Karangploso. Nursing News : Jurnal Ilmiah Mahasiswa Keperawatan, 1(2), 35-44.

Herdiani, N. (2019). Hubungan Imt Dengan Hipertensi Pada Lansia Di Kelurahan Gayungan Surabaya. Medical Technology and Public Health Journal, 3(2), 183-189. https://doi.org/10.33086/mtphj.v3i2.1179

Karim, N. A., Onibala, F., \& Kallo, V. (2018). Hubungan Aktivitas Fisik Dengan Derajat Hipertensi Pada Pasien Rawa tJalan Di Wilayah Kerja Puskesmas Tagulandang Kabupaten Sitaro. Jurnal Keperawatan, 6(1). 
Kemenkes RI. (2015). Rencana Strategis Kementerian Kesehatan Tahun 20152019.

Kowalski, R. E. (2010). Terapi Hipertensi: Program 8 Minggu Menurunkan Tekanan Darah Tinggi dan Mengurangi ResikoTekanan Jantung dan Stroke Secara Alami. Qanita.

Mahmudah, S., Maryusman, T., Arini, F. A., \& Malkan, I. (2016). Hubungan Gaya Hidup Dan Pola Makan Dengan Kejadian Hipertensi Pada Lansia Di Kelurahan Sawangan Baru Kota Depok Tahun 2015. Jurnal Biomedika, 3947.

Nursalam. (2015). Metodologi Ilmu Keperawatan (Ed 4). Salemba Medika.

Proverawati, A. (2010). Obesitas dan Gangguan Perilaku Makan Pada Remaja. Nuha Medika.

Pudjiastuti, R. D. (2013). Penyakit-penyakit Mematikan. Nuha Medika.

Ramadhani, E. T., \& Sulistyorini, Y. (2018). Hubungan Kasus Obesitas Dengan Hipertensi Di Provinsi Jawa Timur Tahun 2015-2016. Jurnal Berkala Epidemiologi, 6, 35.

Rihiantoro, T., \& Widodo, M. (2018). Hubungan Pola Makanan Aktivitas Fisikdengan Kejadian Hipertensi di Kabupaten Tulang Bawang. Jurnal Ilmiah Keperawatan Sai Betik, 13(2).

Rina Andriani. (2017). Hipertensi Pada Laki-Laki Dewasa Awal ( 18-40 Tahun ) Di Wilayah Puskesmas Bromo Medan Tahun 2017. Ilmu Kesehatan Masyarakat, 68-73.

Sari, I. E., Kaunang, W. P. J., \& Ratag, B. T. (2019). Hubungan Antara Kebiasaan Mengonsumsi Minuman Beralkohol Dan Aktivitas Fisik Dengan Kejadian Hipertensi Di Desa Karumenga Kecamatan Langowan Utara Kabupaten Minahasa. Jurnal KESMAS, 8(4), 7-12.

Suiraoka. (2012). Penyakit Degeneratif (Cetakan Pe). Nuha Medika.

Ulumuddin, I., \& Yhuwono, Y. (2018). Hubungan Indeks Massa Tubuh Dengan Tekanan Darah Pada Lansia Di Desa Pesucen, Banyuwangi Relations of Body Mass Index With Blood Pressure Old People in Pesucen, Banyuwangi. Jurnal Kesehatan Masyarakat Indonesia, 13(1).

WHO. (2015). World Health Statistics 2015.

Yanti, T., Fitrianingsih, N., \& Hidayati, A. (2018). Hubungan Obesitas Dengan Kejadian Hipertensi Pada Usia Dewasa. Jurnal Persatuan Perawat Nasional Indonesia (JPPNI), 3(1), 8. https://doi.org/10.32419/jppni.v3i1.97

Yonata, A., \& Pratama, A. S. P. (2016). Hipertensi sebagai Faktor Pencetus Terjadinya Stroke. Jurnal Majority, 5(3), 17-21. 